\title{
Pharmacokinetic Parameter Original Result Unit
}

National Cancer Institute

\section{Source}

National Cancer Institute. Pharmacokinetic Parameter Original Result Unit. NCI

Thesaurus. Code C87982.

The unit of measure first specified in a pharmacokinetic parameter assessment. 